\title{
LIFELONG LEARNING - A FACTOR OF PROFESSIONAL REALIZATION Mariya Teneva ${ }^{1}$, Zlatka Zhelyazkova $^{2}$
}

\begin{abstract}
The article deals with the problem of full professional realization of the personality based on permanent enrichment of knowledge, skills and competences. The modern man lives in a society defined as a "knowledge society." In order to keep up-to-date in the labor market, where some professions are losing their importance and the need for new ones is created, they are faced with the need to learn throughout their whole life. The article presents the results of an empirical study. The study covers 66 graduate students in a one-year specialization to acquire a new vocational qualification "teacher", who study at the Faculty of Education at Trakia University in Stara Zagora, Bulgaria. The results indicate that the sustainability of the idea of lifelong learning is being considered and realized by representatives of different generations. The age of the respondents varies over a very wide range - from 23 to 56 years of age. The persons surveyed clearly differentiate the strengths and weaknesses of their studies at the university. They express their satisfaction with the theoretical and practical training they have received in the higher education institution. They unambiguously define their motives for acquiring a new professional qualification - from the realized opportunity for a new professional realization, competitiveness in the labour market, desire for change, to the realization of an unfulfilled dream.
\end{abstract}

UDC Classification: 374, DOI: https://doi.org/10.12955/pss.v1.79

Keywords: education, lifelong learning, personal self-realization

\section{Introduction}

The contemporary man faces the challenge of living in a dynamic time. The rapid changes that are taking place in science and technology are affecting the development of the world economy. Some professions are dying out, new ones are emerging. In the labour market, there is a need for specialists with new professional competences. Is the education system ready to respond quickly to the needs of the labour market? Are conditions for continuing qualification and permanent learning of the individual being created? Is there any feedback between educational institutions and the users of educational services? These are questions that need to be answered in order to overcome the deficiencies identified and to support the realization of the contemporary personality in social and professional terms. This article presents the problems of the permanent learning of the modern man, understanding their role in acquiring new professional skills and competences and making them a factor for successful realization in the labour market.

\section{Data and Methodology}

The article presents the results of an empirical study. The survey involved 66 respondents. Of these, 56 are women and represent $84.84 \%, 10$ are men and represent a share of $15.15 \%$. They range in age from 23 to 56 year-olds. The distribution of the respondents by age is as follows: from 20 to 30 yearolds $-19,69 \%$; from 31 to 40 year-olds $-46,96 \%$; from 41 to 50 year-olds $-28,78 \%$; over 50 yearolds $-4.54 \%$. All of them are trained in a one-year specialization for the acquisition of additional qualification "teacher" at the Faculty of Education at Trakia University, Stara Zagora, Bulgaria. All trainees hold diplomas for higher education obtained at different universities in Bulgaria. The purpose of their one-year continuing education is to acquire new professional skills and competences that will enable them to pursue the profession of a teacher in the field of the specialty they have already validated through their diploma. The research was realized through a specially designed testquestionnaire. The test-questionnaire is aimed at differentiating factors for effective professional realization of the personality. It is divided into three parts. The first part of the questions is aimed at establishing the level of satisfaction of the respondents with the level of theoretical and practical training in the university they have graduated. The second part focuses on differentiating the strengths and weaknesses of their university studies. The third part of the test questionnaire aims to reveal the leading motivatives of the students for acquiring a new professional qualification - that of a teacher.

The research methods used are: content analysis, test, SWAT analysis, percentage analysis.

\section{Results and Discussion}

The results of the study indicate that the idea of lifelong learning, as a prerequisite for full-fledged professional realization, is being accepted and conceptualized by an increasing number of people from different age groups. It is of interest to us as researchers that the smallest share by value are the target

\footnotetext{
${ }^{1}$ Trakia University, Faculty of Education, Stara Zagora, Bulgaria, m.s.teneva@abv.bg

${ }^{2}$ Trakia University, Faculty of Education, Stara Zagora, Bulgaria, zlato6ki@abv.bg
} 
groups of the youngest and the oldest graduate students. The youngest graduate students are 23 years old and represent $4.54 \%$ of the respondents. The oldest graduate students are 53 years old and also account for a share of $4.54 \%$. The largest share belongs to the group of respondents aged between 31 and 40 year-olds. Their share amounts to $46.96 \%$, followed by the group of $41-50$ year-olds, whose share is $28.78 \%$. Altogether, the proportion of graduates aged between 31 and 50 included in the study is $75.74 \%$. The results indicate that the modern man has long rejected the notion that education is a priority for the age of childhood and adolescence. In order for the personality to be adequate to the ever changing conditions, it is necessary to make a focused effort for their permanent selfimprovement, which includes lifelong learning. These ideas are presented in the European Qualifications Framework for Lifelong Learning. This document regulates the possibilities for the integration of different qualification systems, aiming at facilitating the transfer of qualifications between countries, making the competences practicable, both at national and European level. (European Qualifications Framework for Lifelong Learning (EQF)). Ideas for optimizing the educational process through lifelong learning are presented in the UNESCO 21st Century Education Report, which states that the realization of the idea of lifelong learning can be achieved through four main pillars: learning how to live with others, learning how to study, learning how to act, learning how to live/exist (Learning: The treasure within. Report to UNESCO of the International Commission on Education for the Twenty-first Century). In line with these ideas, a reference framework for key competences has been developed. It regulates the competences that need to be formed through training within the Member States of the European Union. This idea is aimed at facilitating the more flexible transfer of specialists in different economic sectors across the pan-European area. Seven key competences for lifelong learning have been identified: native language communication, foreign language communication, mathematical competences and basic science and technology knowledge, digital competence, learning skills, social and civic competences, initiative and entrepreneurship, cultural awareness and creativity (Lifelong learning - key competences). The aforementioned areas of competence are differentiated as significant for the complete social and professional realization of the modern man. Education is conceived as a prerequisite for the formation of key competences guaranteeing fast adaptability, high professionalism and satisfaction of the person from the degree of its realization. The Organization for Economic Co-operation and Development (OECD) presents ideas according to which the level of education is linked to the level of income and employment opportunities of the people. The OECD's Annual Educational Survey presents information on participants in the educational process, the investment made in education, the functioning of educational systems and their results (OECD, 2009). The Organization for Economic Co-operation emphasizes the fact that the effectiveness of the educational systems is not solely linked to the amount of money invested in education. They are effective in societies that make education a top priority. The results of this study indicate that the above-mentioned valuable ideas of the European Union for fullfledged work realization of the person included in the normative documents reach the specialists on the Bulgarian labour market and are considered with the necessary significance. This is confirmed not only by the wide age range of the respondents, but also by the variety of basic professions they have acquired in various higher education institutions in Bulgaria. Specialists for the acquisition of a new vocational qualification "teacher" included in this study have the following set of professions: economists - 42,35\%; engineers - $22.73 \%$; social workers - $7.60 \%$; psychologists - $6.10 \%$; choreographers - 4,55\%; veterinarians - 4,55\%; athletes - 4,55\%; agronomists - 3.03\%; philologists $-3.03 \%$; biologists $-1.51 \%$. From the distribution of the trainees by profession it can be summarized that the highest degree of uncertainty about their professional realization is experienced by specialists with higher economic education. Manufacturing enterprises are being closed, companies are being restructured, banks are being consolidated, priority sectors of the national and world economy are developing, which provokes employees in the fields of accounting, banking, engineering, social sciences etc. to seek new career opportunities through continuing training and qualification. The interrelation between continuing qualification and career development is revealed in the scientific research works of J. Merdzhanova, I. Petkova, J. Yankova. Merdzhanova reveals the content set of career education and its focus on the formation of career management skills. (Merdzhanova, 2012). Petkova links career choices to career development (Petkova, 2012). Yankova points out that if career development is external, the visible to the individual and society secment, then professional qualification is internal, meaningful (Yankova, 2014). 
The first part of the test-questionnaire includes 2 questions aimed at revealing the respondents' satisfaction with the quality of their theoretical and practical preparation and the training they received in the higher education institutions they had graduated from. The respondents were given for both questions to choose one of the three options provided: a) I am completely satisfied; b) I am partially satisfied; c) I am not satisfied. The results are presented in Figure 1:

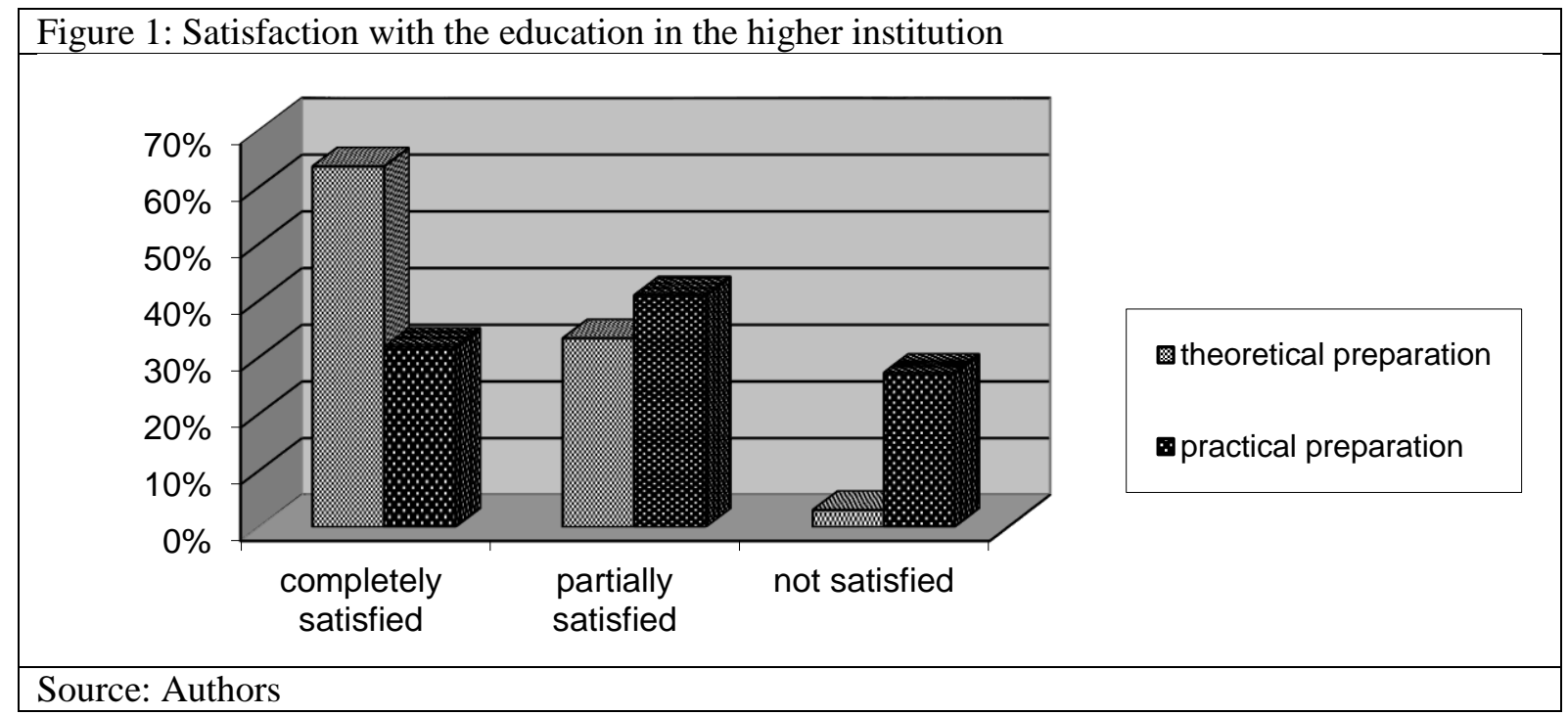

From the graph in Fifure 1 it can be established that the respondents are characterized by a higher degree of satisfaction with the quality of their theoretical preparation than that in the practical one. $63.63 \%$ of the trainees are completely satisfied with the quality of their theoretical training, while only $31.31 \%$ of them are fully satisfied with the quality of their theoretical training. $33.33 \%$ of the respondents are partially satisfied with their theoretical background and $40.91 \%$ are satisfied with their practical background. Only $3.04 \%$ of the respondents were not satisfied with the quality of their theoretical education at the university, and dissatisfaction with the quality of the practical training at the university was characteristic of $27.27 \%$ of the surveyed persons. The possibility of answering 2 questions (1. about satisfaction with theoretical training and 2. about satisfaction with practical training) by choosing from 3 possible options makes the described below 6 combinations available. The highest number of respondents indicated complete satisfaction with both their theoretical and practical training at the higher education institution, and they answered with "a-a" for both questions. They represent $31.82 \%$. The second position is taken by the respondents who are completely satisfied with the level of their theoretical background but are partially satisfied with their practical training at the higher education institution. The answer options for questions 1 and 2, respectively, are "a-b". Their share is $21.21 \%$. The third position is taken by the respondents who are partially satisfied with both their theoretical and practical level. For questions 1 and 2, they choose the "b-b" answers. The share of these respondents is $19.70 \%$. The fourth position is occupied by the graduate students who are partially satisfied with their theoretical background but are not satisfied with their practical training at the university they have graduated from. They represent a share of $13.63 \%$. The first and second questions are chosen by the answers "b-c". The fifth position is taken by the respondents who are completely satisfied with the level of their theoretical, but are not satisfied with the level of their practical preparation. They provide, respectively, the following answers for questions 1 and 2, a-c. They represent a share of $10.61 \%$. The sixth position is taken by the respondents who are not satisfied with either the level of theoretical or their practical training at the university. For both questions, they choose the answers "c-c". The share of these trainees represents 3.04\%. The results reveal a tendency of higher satisfaction of the respondents with the level of their theoretical preparation than the practical one. While more than two-thirds of them are fully satisfied with their theoretical preparation, only one-third of them are fully satisfied with their practical training in the higher school yhey have graduated from. This established trend highlights the need to increase the hours of practical training in the curricula of the higher education institutions in Bulgaria. Differences in the training of higher education professionals in the European area are presented by I. Prokop, according to whom the differences can be sought both in the type of institution in which they are prepared and in the 
educational programs under which the training is provided, in the organization and structure of preparation, in the traditions of the educational systems of individual countries, etc. (Prokop, 2012). Traditionally, the Bulgarian education system is focused on theorizing of education. Often, students are not afforded the opportunity to discover the practical projections of theoretical knowledge provided to them by university professors at a high academic level.

The purpose of the second part of the test-questionnaire is to identify the strengths and weaknesses of university education, respectively. This would help to find a logical explanation for the level of satisfaction or dissatisfaction of the respondents with their preparation in higher education and their subsequent professional realization in the labour market. Respondents were given the opportunity to construct more than one answer on each of the questions, suggesting that the total would exceed $100 \%$. The largest is the number of respondents emphasizing the in-depth theoretical background they perceive as a strength of their university studies. Such an answer was formulated by $87.87 \%$ of the trainees. We find a high level of correlation between the results indicating the complete satisfaction of the respondents with the level of their theoretical preparation and the high assessment they give to this particular feature of the training. In the second position, a strong side of university education is considered to be the good communication between teachers and students. Such an answer was given by $63.63 \%$ of the respondents. The third position among the strengths of university education is the good material base and facilities that universities provide as a learning environment. This opinion is shared by $57.57 \%$ of the surveyed persons.

The weakness of university education which is considered by the trainees to be of the highest degree is the absence of sufficient hours for practical training. This was stated by $75.75 \%$ of the respondents. Pointing out this weakness in higher education is correlated with the differentiated low level of satisfaction of the trainees with their practical training at the universities they have graduated from. The second position is taken by the opinion of the respondents that in the curricula of universities there is a large number of courses which they define as "unnecessary", since they do not find their practical projection towards the particular profession they are mastering. This answer is valid for $54.54 \%$ of the subjects surveyed. We find a correlation between the first mentioned weakness of the education in the higher education institutions and the third position which is expressed in the absence of contacts between the students and employers of the real business in the university educational stage. Such an answer is valid for $51.51 \%$ of the respondents. As a result of the conducted SWAT analysis, we can conclude that in the curricula of the higher education institutions in Bulgaria it is necessary to increase the share of hours for practical training and to seek out opportunities for a closer link between training and the users of the educational services, such as the employers in the business.

The third part of the test-questionnaire focuses on differentiating leading motives that provoke the individual to commit to lifelong learning. Motivation can be seen as a kind of a driver of human behaviour. Stamatov and Minchev point out that we cannot directly observe the motives, but for their existence we are judged by what people say, feel, do (Stamatov \& Minchev, 2005). The notion that motivation is related to behaviour and cannot be measured beyond its relationship to it is shared by Baron and Schunk. They define motivation as an internal process that activates, directs, and sustains behaviour over time (Baron, 1998; Schunk, 1990). A similar view is shared by Gage \& Berliner (Gage \& Berliner, 1984), who liken the motivation of the motor (the intensity) and the steering wheel (the direction) of the car. The trainees were asked the question: "What are your motives for acquiring a new professional qualification?". The largest number of respondents indicated that the acquisition of a new vocational qualification as a teacher was motivated by their desire to take on a new challenge in their lives. This answer is typical for $30.30 \%$ of the respondents, most of whom are in the age range of 30-40 year-olds. This finding provokes us to believe that people in the specified age range are most prone to accepting new challenges. The next leading motive, according to the respondents, is their interest in the teaching profession. Such a response is valid for $28.78 \%$ of the trainees covered by the study. Brad Olsen believes that entering and remaining in the teaching profession is influenced by the professional identity. He presents his holistic model of identity in the teaching profession which incorporates the individual's previous personal and professional experiences, their training and career plans (Olsen, 2008). Career and personal growth are the motivating factors for $22.72 \%$ of the respondents who study in the specialization which is the focus of the study. The motivation for acquiring a new professional qualification "teacher" for $13.63 \%$ of the respondents was provoked by 
the pursuit of the acquisition of prestige and higher material remuneration. In the past 30 years, after the democratic transition, Bulgaria has maintained a steady tendency for the incomes of workers in the field of education to be lower than the national average wage. The shortage of pedagogical staff in the labor market provokes the government bodies of the state to take measures to increase the salaries of teachers several times in order to increase the attractiveness of the teaching profession. The results of the study indicate that the government's efforts to increase the prestige of the teaching profession by increasing salaries are in the right direction and are already yielding positive results. For $4.54 \%$ of the respondents, the leading motive for acquiring a new vocational qualification "teacher" is related to the fulfillment of their childhood dream. In her research on the factors of professional choice M. Teneva reveals a triadic relationship between the needs-abilities-interests of the individual (Teneva, 2016). A person's dreams are interrelated with their sphere of need. A. Maslow "hierarchises" human needs in a pyramidal structure (Maslow, 2002) and R. Sternberg binds the needs to the personality's abilities and relates them to intelligence in the a triarchical theory of human intelligence (Sternberg, 2012). In attempting to meet their needs at lower hierarchical levels, man tests his or her abilities and success in this endeavour gives rise to dreams and aspirations to satisfy the needs of higher hierarchical levels. Successful professional realization is at the top of Maslow's pyramid because it is related to the need for self-actualization. Self-actualized people in a professional aspect are characterized by dynamism, initiative, communicativeness, self-acceptance, striving for personal and professional selfimprovement, rapid professional advancement and career growth. We are inclined to accept that these valuable qualities are inherent in the trainees covered in our study.

\section{Conclusion}

The results of the research give reason to conclude that:

Professional choice needs to be considered in light of its going through different stages When the professional choice made does not satisfy the meta-needs of the individual, they are able to carry out a corrective process and in line with the ideas of lifelong learning to make a new professional choice.

The specialists studying for the acquisition of a new vocational qualification "teacher" express higher satisfaction with the quality of their theoretical training compared to their practical training in higher education.

According to the respondents, the strengths of the education in the higher education institutions in Bulgaria are the in the in-depth theoretical training that the students receive, the good communication that is realized between teachers and students and the good material base of the higher education institutions. The weaknesses are the lack of practical training, the ineffective curricula, the lack of a constructive link between future employers and students.

The leading motives for continuing education and training vary widely: from a desire to take on new challenges, through an interest in a particular profession, a desire for career and personal development, to the realization of a foreseeable dream.

\section{References}

Baron, R. A. (1998). Psychology (4 ${ }^{\text {th }}$ ed.). Boston: Allyn \& Bacon.

European Qualifications Framework for Lifelong Learning (EQF)

http://ec.europa.eu/dgs/education_culture/publ/pdf/broch_bg.pdf

Gage, N. L. \& Berliner, D. C. (1984). Educational psychology ( $3^{\text {rd }}$ ed.). Boston: Houghton Mifflin.

Learning: The treasure within. Report to UNESCO of the International Commission on Education for the Twenty-first Centure, http://www.unesco.org/education/pdf/15_62.pdf

Lifelong learning — key competences https://eur-lex.europa.eu/legal-content/EN/TXT/?uri=LEGISSUM\%3Ac11090

Maslow, E. (2002). Motivation and personality [Motivatsiya i lichnost]. Sofia, p. 582

Merdzhanova, E. (2012). European Career Education in Bulgarian Conditions. Pedagogy. Issue 1. [Evropeřskoto karierno obrazovanie v bŭlgarski usloviya. Pedagogika]. Sofia: Publishing House Az Buki, p. 79.

OECD. (2009). Education at a Glance: OECD Indicators, OECD, Paris. http://www.oecd.org/education/skills-beyondschool/43636332.pdf

Olsen, B. (2008). How reasons for entry into the profession illuminate teacher identity development. Teacher Education Quarterly, Summer, 2008. http://eric.ed.gov/PDFS/EJ831706.pdf

Petkova, I. (2012). Training and qualification of the Bulgarian teacher [Podgotovka i kvalifikatsiya na bŭlgarskiya uchitel] Sofia: Sv. Kliment Ohridski.

Prokop, I. (2012). Comparative pedagogy [Sravnitelna pedagogika]. Sofia: Ex-Press. 
Stamatov, R., Minchev, B. (2005). Psychology of man [Psikhologiya na choveka]. Plovdiv: Hermes, p. 266.

Schunk, D. H. (1990). Introduction to the special section on motivation and efficacy. Journal of Educational Psychology, 82, $1-6$.

Sternberg, R. (2012). Cognitive Psychology [Kognitivna psikhologiya]. Sofia: East West.

Teneva, M. (2016). Who is a good teacher? [ Koŭ e dobŭr uchitel?]. Stara Zagora. pp. 10-16.

Yankova, J. (2014). Continuing qualification of the resource teacher. Special pedagogy and speech therapy. Issue 1

[Prodŭlzhavashta kvalifikatsiya na resursniya uchitel. Spetsialna pedagogika i logopediya. Br. 1]. Publishing house: Diamira, p. 54. 